Article

\title{
Preference for Democracy in the Arab World
}

\author{
Mohammed Al-Ississ ${ }^{1}$ and Ishac Diwan ${ }^{2,3, *}$ \\ ${ }^{1}$ School of Business, The American University in Cairo, Cairo, Egypt; E-Mail: alississ@aucegypt.edu \\ 2 Paris Sciences et Lettres, 75006 Paris, France; E-Mail: ishac_diwan@hks.harvard.edu \\ ${ }^{3}$ Harvard Kennedy School, Harvard University, Cambridge, MA 02138, USA \\ * Corresponding author
}

Submitted: 9 September 2016 | Accepted: 19 October 2016 | Published: 14 December 2016

\begin{abstract}
We take a new look at the question of the Arab democratic exception by looking at the preference for democracy among individuals in the Arab world in a comparative context. We use the new sixth wave of the World Value Survey, which was collected between 2012 and 2013, and which included for the first time 12 Arab countries (up from only four in wave 5) and 68 non-Arab countries. We innovate empirically by measuring the preference for democracy over strong rule in a way that, we argue, is more adapted to an understanding of the Arab world than other measures used in past studies. Our statistical analysis reveals a democratic gap in the Arab region compared to global experience, which is especially marked among the more educated individuals, and to a lesser extent among the youth and the middle class. We conclude by discussing the reasons that may explain the Arab exceptionalism, and argue that it is unlikely to be related to culture alone.
\end{abstract}

\section{Keywords}

Arab democratic exceptionalism; Arab Spring; democratic values; emancipation; indoctrination

Issue

This article is part of a multidisciplinary issue of Politics and Governance, edited by Christian Haerpfer (University of Vienna, Austria) and Kseniya Kizilova (Institute for Comparative Survey Research, Austria).

(C) 2016 by the authors; licensee Cogitatio (Lisbon, Portugal). This article is licensed under a Creative Commons Attribution 4.0 International License (CC BY).

\section{Introduction}

In this paper, we re-open the debate about a possible cultural bias against democracy in Arab countries. The interest in understanding the political culture of the Arab countries as a group has risen among policy makers and social activists because of the failure of the popular uprisings of 2011 to deliver political change, and the political chaos that has ensued. There are also more objective reasons to look at the Arab countries as one group because of the cultural, political, and economic similarities between them. On the cultural side, the region shares one language and has one dominant religion. The development of a regional Arab media, and the increased movement of migrants throughout the region have facilitated the movement of ideas. On the political front, "presidents for life" had entrenched autocratic regimes in all countries, save Lebanon (Owen, 2014). Finally, the economies of Arab countries have been dominated by the logic of rents extraction and distributionoil, geopolitical, and regulatory-which have fostered crony relations between state and business that have taxed growth and impeded global integration (Cammett, Diwan, Richards, \& Waterbury, 2015; Chekir \& Diwan, 2014; Henry \& Springborg, 2010). These similarities have revealed themselves most starkly during 2011, when protests in Tunisia led quickly to protests across the Arab world, led by similar political demands for more freedoms, dignity, and economic opportunities.

Our goal is to assess whether citizens in Arab countries desire democracy as much as otherwise similar individuals in the rest of the world. We take advantage of new data released by the World Value Survey (WVS) as its $6^{\text {th }}$ wave, which was collected during $2011 / 2013$, and 
which included 12 Arab countries, and 75 non-Arab countries. ${ }^{1}$ This is in contrast the WVS's $4^{\text {th }}$ and $5^{\text {th }}$ waves, collected around 2000 and 2008, which only included 5 and 4 Arab countries respectively. The new dataset allows for the first time to compare values in a sizable share of the Arab world to values around the world.

The literature focusing on the individual support for democracy in the Arab world is thin. Most existing work concerns the relationship between support for democracy and Islam. While some researchers such as Fish (2002), have found that there is a Muslim democratic deficit, other researchers conclude that at the level of individual preferences, there is no particular democratic deficit connected to being Muslim, whether Muslims are compared to individuals of other religions in heterogeneous societies (Hofmann, 2004), whether individuals of various levels of piety are compared in Arab countries (Tessler, 2002a, 2002b), or whether one compares individuals in Muslim societies to individuals in other societies (Norris \& Inglehart, 2002). Tessler (2002a) and Jamal and Tessler (2008) show, using Arab Barometer data (which is limited to Arab countries), that individuals in Arab countries have a strong desire for democracy, especially among the youth and the educated, but these studies do not compare the intensity of this demand with that emanating from individuals around the world. Indeed, the literature does not look at an Arab specificity in a comparative context largely because micro-data on values covering a large set of Arab countries and international comparators were, until recently, not available. ${ }^{2}$

Besides using a richer dataset, this paper innovates methodologically in several respects. First, it looks at the Arab values in comparison to global values. Second, it asks whether individual characteristics such as education, young age, middle class status, and low religiosity are as "emancipative" in terms of democratic preferences in the Arab world as in the rest of the world. Third, we use a new measure of the "preference for democracy" which we argue is more instructive for the Arab context compared to measures used by other researchers in comparative studies such as Inglehart and Welzel (2005, 2010).

Our empirical work reveals that individuals living in Arab countries do have a lower preference for democracy compared to otherwise similar individuals living in other countries at similar levels of development. We find that the deficit is especially large among the educated, followed by the youth, and the middle class, and it is only explained in small part by the higher extent of religiosity exhibited in the Arab region.
The paper is organized as follows. Section 2 discusses how to measure the preference for democracy. Section 3 evaluates empirically the existence of an Arab exception. Section 4 asks whether this exception is connected with different socio-economic groups. Section 5 looks at civic action. Section 6 conducts robustness tests, and section 7 concludes by discussing the reasons that may be driving these preferences.

\section{Measuring the Preference for Democracy, and Comparing Arab Citizens with the Rest of the World}

We first discuss how to measure individual preferences for democracy. Admittedly, democracy is a multidimensional concept than cannot be reduced to a single variable-there are many forms of it, and people may have different understandings if it. ${ }^{3}$ In this paper however, we do not focus on the type of democracy people aspire to, but rather, on their ranking of democracy, as they understand it, with an alternative regime. When simply asked to rate their (unconstrained) preference for a democratic order, Arabs, like most people around the world, express a high demand for democracy, and especially so among the youth and the educated individuals (Tessler \& Gao, 2005). To get a finer measure, one must measure not just individuals" "raw" support for democracy, but also their rejection of non-democratic alternatives-Inglehart and Welzel (2005, p. 253) suggest that some people may not be "solid democrats" if their support for democracy is offset by parallel support for authoritarian regimes. ${ }^{4}$ Jamal and Tessler (2008) look at this issue more closely in the Arab world. Based on Arab Barometer data, they show that a significant number of individuals polled in the Arab region support both democracy and strong rule. Indeed, when the opinion poll questions become more qualified (for example, would respondents favor a quick or gradual shift to democracy, or whether in spite of problems, democracy is better than other political systems), responses become more ambiguous (Jamal \& Tessler, 2008). They conclude that while many people in the Arab world support democracy in principle, they seem to want to see it implemented gradually, out of a fear that democracies are poor at maintaining order.

A measure of "net" support for democracy is provided by Inglehart and Welzel $(2005,2010)$, who, using WVS questions, subtract from a variable measuring democratic aspirations ("how important is it for you to live in a country that is democratically governed?"), a measure of individual preferences for autocracy ("as a

\footnotetext{
${ }^{1}$ These are: Jordan, Egypt, Palestine, Lebanon, Iraq, Morocco, Algeria, Tunisia, Qatar, Yemen, Kuwait, and Libya. The WVS interviews $1000-3000$ individual per country using polling methods that are meant to produce nationally representative samples.

2 In particular, Gallup data does not include good measure of democratic aspirations, PEW does not have a detailed list of the respondents' characteristics, and the Arab Barometer, which has a deeper coverage of issues surrounding democracy and political Islam, does allow for comparisons with the rest of the world.

${ }^{3}$ And indeed, there is a literature that tries to characterize individual understandings of democracy using various questions related to whether it would be good for the economy, whether it should entail income redistribution, or whether it tends to favor political stability. See for example Cifti (2010) on these issues, for the Muslim countries covered by the WVS.

${ }^{4}$ Inglehart and Welzel (2005) also show this "net" measure behaves better than the "gross" measure of preferences for democracy in terms of its correlation globally with measures of effective democracy.
} 
way of governing your country, what do you think of having a strong leader who does not have to bother with parliament and elections"). ${ }^{5}$ Below, we refer to this measure as NetDemo.

We think however that this definition is too blunt in defining "solid democrats" in the Arab world. It may well be that many Arabs are looking for relatively managed elections as described by Jamal and Tessler (2008), but that this does not necessarily push them to support autocrats "who do not bother with elections". 6 We prefer to measure the (relative) preference for democracy with a variable that allows respondents to rank their preference for democracy relative to "strong rule", but not to such an extreme form of autocracy. Ideally, such a measure would also allow respondents to directly rank alternatives (rather than subtract two ordinal values), and it would rely on more than one question in order to reduce noise.

We have developed what we argue is a more adapted measure to the circumstances where both a full democracy and a repressive autocracy are likely to be viewed by many as undesirable. We compute our measure, which we call "preference for democracy" (PfD), by using 3 questions in the WVS that ask respondents to rank the values provided in 3 separate menus, where each menu includes at least one value connected with democratic ideals ("people have more say in how things are done", "giving people more say in important government decisions", "protecting freedom of speech, progress towards a less impersonal and more humane society") and one with authoritarian (but not openly tyrannical) preferences ("making sure the country has strong defense forces", "maintaining order in the nation", "the fight against crime").
Our measure is also ordered: we rate higher individuals who rank values connected with democracy above those associated with security more frequently. ${ }^{7}$

Table 1 shows the basic statistics for DemoNet, PfD, and their constituent variables: democratic aspirations, and support for strong rule. We also include a measure of democratic grievances (DemoGap), a variable used extensively by Norris (e.g. Norris, 2011), which measures the difference between the answers to a question about the strength of democratic aspirations ("how important is it for you to live in a country that is democratically governed?"), and an assessment of the current situation ("how democratically is your country being governed today?"). Demo gap measures an aspect of the demand for democracy different from DemoNet and PfD: the gap between the extent to which some people like the idea of democracy, and their assessment of how democratic their country actually is. People may have large democratic grievances (so DemoGap will be large), and yet, when asked to rank democracy and strong rule/autocracy, they may still prefer the latter (so PfD or DemoNet would be small).

The three variables DemoNet, DemoGap, and PfD measure different aspects of the demand for democracy. It turns out that while the PfD average is lower in the Arab sample relative to the rest of the world ( 3.0 versus 3.75 average score on a scale of 10 ), the average of DemoGap and DemoNet are larger in the Arab world.

In order to try and understand the character of this regularity, it is useful to examine how these 3 variables are distributed along various socio-economic groups in the Arab and global samples. To do so, we develop below

\footnotetext{
${ }^{5}$ Answers to each of these questions are a number that represent the respondent preference between two extreme possible answers, typically over a (1-10) range. This allows developing various measures of gap by subtracting two variables.

${ }^{6}$ Moreover, the measure treats two ordinal variables as cardinal by subtracting them and expecting the difference to be ordered. While the use of ordinal values cannot be avoided in statistical analysis of opinions, it should be minimized, especially for dependent variables.

${ }^{7}$ For a precise description of how the PfD variable, and other variables used in the paper, are constructed, see the appendix.
}

Table 1. Summary statistics (Global and Arab Datasets, Individual Level, waves 5 and 6).

\begin{tabular}{|c|c|c|c|c|c|c|c|c|}
\hline & \multicolumn{3}{|c|}{ Arab countries } & \multicolumn{3}{|c|}{ ROW } & \multicolumn{2}{|c|}{ All } \\
\hline & Obs. & mean & SD & Obs. & mean & SD & $\min$ & $\max$ \\
\hline Preference for democracy (PfD) & 23036 & 3.00 & 2.52 & 135591 & 3.75 & 2.58 & 1 & 10 \\
\hline Democratic deficit (DemoGap) & 14027 & 3.27 & 3.37 & 125479 & 2.08 & 2.75 & -9 & 9 \\
\hline Democratic gap (DemoNet) & 18660 & 3.76 & 4.24 & 120884 & 3.51 & 3.96 & -9 & 9 \\
\hline Strong Leader & 21348 & 4.54 & 3.36 & 125641 & 4.90 & 3.05 & 1 & 10 \\
\hline Demo aspirations & 21044 & 8.44 & 2.15 & 131341 & 8.40 & 2.03 & 1 & 10 \\
\hline Demo satisfaction & 14177 & 5.14 & 2.75 & 126447 & 6.31 & 2.44 & 1 & 10 \\
\hline Protest & 19725 & 2.89 & 3.13 & 122210 & 3.78 & 3.19 & 1 & 10 \\
\hline Civic engagement & 23183 & 3.67 & 2.70 & 144948 & 3.60 & 2.64 & 1 & 10 \\
\hline Interest in politics & 22467 & 5.13 & 2.67 & 161948 & 5.12 & 2.60 & 1 & 10 \\
\hline Age & 24507 & 38.27 & 14.21 & 138431 & 42.30 & 16.84 & 15 & 99 \\
\hline Education & 24471 & 2.63 & 1.03 & 137600 & 2.94 & .78 & 1 & 4 \\
\hline Religiosity & 24574 & .76 & .42 & 138759 & .35 & .48 & 0 & 1 \\
\hline Inc1 & 23684 & .18 & .38 & 129599 & .18 & .38 & 0 & 1 \\
\hline Inc2 & 23684 & .23 & .42 & 129599 & .20 & .40 & 0 & 1 \\
\hline Inc3 & 23684 & .24 & .43 & 129599 & .28 & .45 & 0 & 1 \\
\hline
\end{tabular}


several sets of multi-level regressions that explain variations in democratic values PfD in relation to variations in individual characteristics, in both the global and Arab samples, following the form:

$$
P f D=a A+b B+c C+\text { error }
$$

Where the matrix $A$ describes individual characteristics, $B$ is a set of country level variables (GDP per capita, time dummies); and $C$ describes the population under study in various ways (dummies for all Arab countries, or for individual Arab countries). For ease of interpretation of the resulting estimated coefficients, we use simple Ordinary Least Square (OLS) techniques (while recognizing that logistical models would be more adapted to the task), and all variables have been standardized. ${ }^{8}$

Our individual controls include age (15-90), education (classified at four levels), religiosity, gender, and income. We measure income with dummies variables (relative to the richest group) to allow for non-linearities of the income effect-in particular, the middle class may be more democratic than both the richer and poorer part of the population, as found by Diwan (2013) in the case of Egypt. Religiosity is measured relative to the values people want to inculcate in their children, in order to avoid gender biases that would arise if we used instead the frequency of attending religious services (since women are not bound to participate in the five daily prayers in Islam). Precise definitions are in the annex.

It is usually believed that values reflect culture and change slowly. A key weakness of opinion polls is that they measure opinions at a particular moment in time, and that these measurements can be influenced by particular events, and end up as non-representative of the true underlying values. In order to both measure the recent state of values, but attempt to neutralize shortterm fluctuations, we pool data from the $5^{\text {th }}$ and $6^{\text {th }}$ waves, which span the period 2000-2013. As a result, our data covers about 160,000 individuals in 80 countries, of which about 25,000 individuals in 12 Arab countries. ${ }^{9}$ The WVS sample size in each country/wave tends to be reasonable and representative (1000 to 3000 respondents). Answers to questions are typically over a range (1-10), allowing us to measure the intensity of particular values. Most of the questions we use span the two last waves. Whenever we have constructed indexes that use the responses to several questions, factor analysis was conducted to ensure that all the variables entered in the index have one unique factor.

\section{Arab Intercept Effect}

We start by investigating the differences between DemoNet and PfD. In the base regression, $A$ includes indi- vidual characteristics (age, education, gender, income, religiosity), B includes only GDP per capita and a time dummy, and $C$ includes an Arab region dummy and its interaction with time. ${ }^{10}$

The results (in Table 2, columns 1 to 3 ) of the estimation of $A$ accord with the main findings of Inglehart and Welzel (2005), which follow the "modernisation" approach (Lipset, 1959) in finding that education, as a core emancipative value, drives the preference for democracy. Indeed, we find that both measures of democratic values rise with education. The effect of age and income are however different. DemoNet rises with age, while $P f D$ is higher among the youth. This is an important difference, as the first result does not accord well with the wellestablished claim of the modernization school of thought according to which younger generations should be more emancipated (Ingleheart \& Welzel, 2005). In addition, we find that DemoNet has no relation to income, while PfD is highest among the lower middle class, another desirable feature in light of the same literature on the role of the middle class in consolidating democracy. The PfD measure differs from DemoNet in two other ways-it decreases with religiosity, and it is higher among females, relative to males (but both effects are small). Finally, the effect of development, as measured by InGDPc is positive and significant for PfD (again, as suggested by modernization theory) but not significant for DemoNet. Thus, our PfD variable behaves in more intuitively appealing ways than DemoNet on several important accounts. The variable DemoGap behaves in ways similar to DemoNet with respect to age and education. ${ }^{11}$

What of the Arab exception? The results in Table 2 show again important divergences among the two measures. DemoNet shows the Arab region as having a premium for (net) democracy of $+10 \%$, as suggested by the simple averages discussed above, while our variable PfD shows a deficit of $8 \%$. DemoGap also shows a premium of $14 \%$. Since we are using standardized forms for our variables, with a mean of 0 and an SD of 1 , this should be interpreted as a gap of $8 \%$ below the global average (which is 3.75-see Table 1), expressed in terms of units of standard deviation of the global distribution of PfD (which is 2.58). Note that this estimated democratic deficit is smaller than that suggested by the raw averages in Table 1 . This must be due to net composition effects, the Arab region being much more religious and a bit less educated than the global average, two factors that reduce PfD (but it is also younger, which creates an offsetting positive effect on PfD).

The Arab premium connected to DemoNet is explained by the fact that while Arab citizens have slightly higher democratic aspirations compared to individuals around the world (column 5), their demand for a hard au-

\footnotetext{
${ }^{8}$ Standard errors are clustered at the country level.

${ }^{9}$ We have left Bahrain out, as we have found its data to be overly biased towards educated citizens and thus not to be reliable.

10 The time effect in the Arab region is given by the Arb1 dummy, which refers to the 4 countries with data in waves 5 and 6 (which are Morocco, Egypt, Jordan, and Iraq), multiplied by a wave 6 dummy variable. It thus shows the trend among these 4 countries between waves 5 and 6 .

11 Although this is less of a concern since there is no presumption that grievances should behave like core values with respect to modernization-see Norris (2011, p. 243) on this.
} 
tocratic rule is way below that of the rest of the world (ROW)-see column 4. The special dislike for a hard autocratic rule among Arabs is probably related to the catastrophic history of dictators in the region. On the other hand, their DemoGap premium is due to the fact that they rate their regimes as less democratic than in the ROW (column 6). This again is understandable, since their countries are indeed much less democratic than other countries around the world (Freud \& Jaud, 2013). In effect, these results indicate that more than in the ROW, Arabs aspire for both more democracy and less autocratic rule, as they have too little of the first and too much of the second.

But when asked to rank democracy and strong rule (and not hard autocracy), our result in Table 1 indicates that many Arabs tend to prefer the latter, even when they dislike hard dictators. ${ }^{12}$ As a result, they end up below the global averages on PfD, even though they register a premium on the measure of unconstrained aspirations (DemoGap), and of hard autocracy (DemoNet), as if these end up choosing among the lesser of evils. For us, this tension between aspirations and a hard reality is at the heart of the Arab autocratic specificity. ${ }^{13}$ In the rest of the analysis, we will focus on the PfD variable to measure the preference for democracy, as we believe that, based on the results above, this variable characterizes Arab preferences regarding the type of regime they aspire to in a finer and more useful way than the net measure DemoNet of Inglehart and Welzel (2005). ${ }^{14}$

It can be noted that while we have weak evidence for the movement of Arab opinions over time, since they are restricted to four countries, PfD took a small hit after the 2011-2012 uprisings in the 4 countries in the sample, dropping by $3 \%$ on average (but not significant), but at a time when the global trend was also negative. If this trend was applied to the sample of 12 countries, in wave 5, just before the "Arab Uprisings", the gap must have been of a similar magnitude. ${ }^{15}$

\section{The Effect of Individual Arab Characteristics on PfD}

The country-wide level differences that we have observed above between the PfD of citizens of Arabs countries and the rest of the world may reflect differences among all citizens, or they may be due to differences among particular socio-economic groups. Identifying such group differences would help in characterizing better the Arab specificity. We thus extend the results of Tables 2 by looking more in depth at the Arab specific effects of individual characteristics on PfD by adding an Arab dummy variable interacted with individual characteristics in the regression model. These effects will measure possible deviations from the global norms. To recall, we had found that within the global sample, PfD is higher among the middle class (Inc2), the youth, and the educated. Is the structure of individual preferences for PfD different in Arab countries? It is clear from Table 3 that the answer is Yes, and that the main ways in which the Arab world is different are, in order of importance, the effects of education, and then of age and class, which are all less emancipative with respect to PfD than in the rest

\footnotetext{
12 The correlation coefficient between PfD and Strong Leader is -0.15 in the Arab world, indicating that while these two values are not that closely connected.

13 Jamal and Tessler (2008) relate this Arab specificity to a special concern about instability. See our interpretation in the concluding section.

14 We are however not making the case that our measure is always superior to DemoNet. It may be the case that when focusing on other countries or regions, where political opinions are polarized between democrats and populists, the latter measure is more useful.

15 This is consistent with the findings of Tessler and Robbins (2014) who shows, based on Arab barometer micro-data that cover eight Arab countries, that the uprisings of 2011 have not affected preferences for democracy in significant ways.
}

Table 2. Global determinants of preference for democracy (PfD), with Arab intercept effect.

\begin{tabular}{lccccccccc}
\hline & $(1)$ & $(2)$ & $(3)$ & $(4)$ & $(5)$ & $(6)$ & $(7)$ & $(8)$ & $(9)$ \\
\hline & PfD & $\begin{array}{c}\text { DemoGap } \\
{[5-6]}\end{array}$ & $\begin{array}{c}\text { DemoNet } \\
{[5-4]}\end{array}$ & $\begin{array}{c}\text { Strong } \\
\text { Leader }\end{array}$ & $\begin{array}{c}\text { Demo. } \\
\text { aspiration }\end{array}$ & $\begin{array}{c}\text { Demo. } \\
\text { satisfaction }\end{array}$ & $\begin{array}{c}\text { Protest } \\
\text { Civic }\end{array}$ & $\begin{array}{c}\text { Interest } \\
\text { engagement } \\
\text { in politics }\end{array}$ \\
\hline age & $-0.06^{* * *}$ & $0.05^{* * *}$ & $0.06^{* * *}$ & -0.02 & $0.07^{* * *}$ & 0.00 & $0.09^{* * *}$ & -0.02 & $-0.04^{* *}$ \\
education & $0.06^{* * *}$ & $0.13^{* * *}$ & $0.08^{* * *}$ & $-0.04^{*}$ & $0.10^{* * *}$ & $-0.07^{* * *}$ & $0.13^{* * *}$ & $0.15^{* * *}$ & $0.13^{* * *}$ \\
female & 0.01 & $-0.01^{* * *}$ & -0.00 & -0.00 & -0.01 & $0.01^{*}$ & $-0.10^{* * *}$ & $-0.08^{* * *}$ & $-0.08^{* * *}$ \\
religiosity & -0.02 & -0.00 & -0.01 & 0.01 & -0.00 & 0.01 & -0.00 & -0.03 & -0.01 \\
inc1 & -0.00 & $0.08^{* * *}$ & -0.00 & -0.01 & -0.01 & $-0.11^{* * *}$ & $-0.05^{* * *}$ & $-0.05^{* * *}$ & $-0.03^{* *}$ \\
inc2 & $0.02^{* *}$ & $0.04^{* * *}$ & -0.00 & -0.01 & $-0.02^{* *}$ & $-0.07^{* * *}$ & $-0.04^{* * *}$ & -0.02 & -0.01 \\
inc3 & 0.01 & $0.03^{* * *}$ & -0.01 & -0.01 & $-0.02^{* * *}$ & $-0.06^{* * *}$ & $-0.02^{* * *}$ & -0.02 & -0.01 \\
Ingdpc & $0.11^{* * *}$ & -0.05 & 0.05 & -0.05 & 0.02 & $0.09 *$ & $-0.06^{*}$ & $0.21^{* * *}$ & $0.08^{* *}$ \\
ARB & $-0.08^{* *}$ & $0.14^{* * *}$ & $0.10^{* *}$ & $-0.11 * * *$ & $0.05^{*}$ & $-0.13^{* *}$ & 0.05 & -0.08 & -0.03 \\
wave6 & $-0.05^{*}$ & -0.02 & $-0.12^{* * *}$ & $0.09 * *$ & $-0.10^{* * *}$ & -0.05 & -0.03 & $-0.13^{* * *}$ & $-0.08^{* *}$ \\
w6*ARB1 & -0.03 & 0.02 & -0.07 & 0.09 & 0.01 & -0.01 & -0.02 & $-0.05^{* * *}$ & $-0.06^{* *}$ \\
$N$ & 141914 & 126530 & 126217 & 132087 & 137278 & 127428 & 146730 & 131104 & 127652 \\
adj. $R^{2}$ & 0.04 & 0.04 & 0.03 & 0.02 & 0.02 & 0.04 & 0.04 & 0.12 & 0.05 \\
\hline
\end{tabular}

Notes: OLS, uses WVS waves 5 and 6 . Standardized beta coefficients. Variables are defined in the annex. ARB is a dummy for 12 Arab countries included in wave 6. ARB1 is a dummy for the four Arab countries included in wave 5. ${ }^{*} p<0.10, * * p<0.05, * * * p<0.010$. 
Table 3. Determinants of PfD in Arab countries, with Arab specific slope effects.

\begin{tabular}{|c|c|c|c|c|c|c|c|c|c|}
\hline & (1) & (2) & (3) & (4) & (5) & (6) & (7) & (8) & (9) \\
\hline & PfD & $\begin{array}{c}\text { DemoGap } \\
{[5-6]}\end{array}$ & $\begin{array}{c}\text { DemoNet } \\
{[5-4]}\end{array}$ & $\begin{array}{l}\text { Strong } \\
\text { Leader }\end{array}$ & $\begin{array}{c}\text { Demo. } \\
\text { aspiration }\end{array}$ & $\begin{array}{c}\text { Demo. } \\
\text { satisfaction }\end{array}$ & Protest & $\begin{array}{c}\text { Civic } \\
\text { engagement }\end{array}$ & $\begin{array}{l}\text { Interest } \\
\text { in politics }\end{array}$ \\
\hline age & $-0.06 * * *$ & $0.03 * * *$ & $0.05^{* * *}$ & $-0.02 * * *$ & $0.07 * * *$ & $0.03 * * *$ & $-0.01 * *$ & -0.01 & $0.09 * * *$ \\
\hline education & $0.10 * * *$ & $0.10 * * *$ & $0.12 * * *$ & $-0.08 * * *$ & $0.11 * * *$ & $-0.02 * * *$ & $0.18 * * *$ & $0.17^{* * *}$ & $0.11 * * *$ \\
\hline female & 0.00 & $-0.02 * * *$ & -0.00 & -0.00 & $-0.01 * * *$ & $0.01 * * *$ & $-0.06 * * *$ & $-0.06 * * *$ & $-0.10 * * *$ \\
\hline Religiosity & $-0.02 * * *$ & $-0.01 * * *$ & 0.00 & 0.00 & 0.01 & $0.02 * * *$ & $-0.01 * * *$ & -0.03 & -0.01 \\
\hline inc1 & $0.01 * * *$ & $0.07 * * *$ & -0.00 & $-0.01 * * *$ & $-0.02 * * *$ & $-0.10 * * *$ & $-0.01 * * *$ & $-0.04 * *$ & $-0.06 * * *$ \\
\hline inc2 & $0.02 * * *$ & $0.05 * * *$ & -0.00 & $-0.02 * * *$ & $-0.03 * * *$ & $-0.07 * * *$ & $-0.01 * *$ & -0.02 & $-0.05 * * *$ \\
\hline inc3 & $0.01 * * *$ & $0.03 * * *$ & $-0.01 * * *$ & -0.01 & $-0.03 * * *$ & $-0.06 * * *$ & $-0.01 *$ & -0.01 & $-0.03 * * *$ \\
\hline InGDPc & $-0.33 * * *$ & $0.44 * * *$ & $0.16 * * *$ & $-0.29 * * *$ & 0.02 & $-0.39 * * *$ & $0.48 * * *$ & $0.19 * * *$ & $-0.07 * *$ \\
\hline ARB & $0.11^{*}$ & $-0.20 * * *$ & 0.03 & -0.03 & -0.04 & $0.15^{* * *}$ & -0.11 & 0.14 & $-0.15^{*}$ \\
\hline Age ${ }^{*}$ ARB & $0.03 * * *$ & 0.01 & $-0.03 * * *$ & $0.02 * * *$ & $-0.03 * * *$ & $-0.04 * * *$ & $-0.05 * * *$ & $-0.05^{* *}$ & 0.01 \\
\hline Edu*ARB & $-0.07 * * *$ & 0.01 & $-0.05 * * *$ & $0.05 * * *$ & $-0.03 * *$ & $-0.03 * *$ & $-0.12 * * *$ & $-0.13 * * *$ & $0.16^{* *}$ \\
\hline Fem*ARB & $0.01 * * *$ & 0.00 & 0.00 & -0.00 & $0.01 * *$ & $0.01 * *$ & $-0.06 * * *$ & $-0.04 * *$ & -0.00 \\
\hline Relig*ARB & -0.00 & $0.02 * * *$ & $0.04 * * *$ & $-0.03 * * *$ & $0.03 * * *$ & $-0.01 * *$ & $0.02 * *$ & -0.00 & 0.01 \\
\hline inc ${ }^{*} A R B$ & $-0.01 * * *$ & $0.01^{* *}$ & $0.01^{* *}$ & $-0.01 * * *$ & 0.00 & $-0.01 * * *$ & $-0.01 * * *$ & -0.02 & 0.02 \\
\hline inc $2 * A R B$ & $-0.02 * * *$ & -0.00 & 0.00 & $0.01^{*}$ & 0.00 & 0.00 & -0.01 & -0.02 & $0.03^{* *}$ \\
\hline inc $3^{*} A R B$ & 0.00 & -0.00 & 0.00 & 0.00 & -0.00 & -0.00 & $-0.01 * * *$ & -0.02 & 0.01 \\
\hline$N$ & 141914 & 126530 & 126217 & 132087 & 137278 & 127428 & 127761 & 132019 & 145178 \\
\hline $\operatorname{adj} . R^{2}$ & 0.10 & 0.13 & 0.18 & 0.17 & 0.08 & 0.19 & 0.15 & 0.12 & 0.04 \\
\hline
\end{tabular}

Notes: See notes in Table 2 . Also include time dummies (not shown). Standardized beta coefficients. $* \mathrm{p}<0.10, * * \mathrm{p}<0.05, * * *$ $p<0.010$.

of the world (as the variables have been normalized, the size of the effects can be directly compared in our regression results). As noted above, a fourth factor that stands out is religiosity, because of a large compositional effect, rather than because religiosity influences values in the Arab region differentially.

First, the effect of education on PfD is very much muted in the Arab region $(+3 \%=+10 \%-7 \%)$ relative to the rest of the world, $(+10 \%)$. This means that as an individual moves from uneducated to being a university graduate, which is about 4 SDs on the education scale (see Table 1), her PfD rises by $40 \%$ globally, but only by $12 \%$ in the Arab world-a very large difference. It is noteworthy that there is a similar, albeit smaller effect for Gap 2, the measure on preference for democracy relative to a hard autocracy. Thus, as in the ROW, education emancipates, but it does so much less in the Arab world compared to the global experience, resulting in low national averages on PfD. The result that education emancipates politically in the Arab world is not new (Jamal, 2006; Tessler, 2002), but that it does so much less than elsewhere is.

Second, the effect of young age on PfD is smaller in the Arab region than in the rest of the world-the net Arab slope relative to age is $-3 \%(-6 \%+3 \%)$, compared to a global slope of $-6 \% .{ }^{16}$ So for example when comparing a person in her 20s, with another in her 60s (about 3 SDs on the age scale), holding all other personal characteristics at their global means, the young would have an excess on PfD relative to the old of $18 \%$ in the ROW, and only of $9 \%$ in the Arab region. Here too, the new result is not that youth are more emancipated in the Arab region compared to the old, but that they are less so compared to global experience.

Third, the effect of religiosity is significant, negative, and similar in the Arab region and in the ROW, but this translates into a larger PfD gap in the region given that it is much more religious than the ROW (.76 versus .35 on a scale of $0-1$, see Table 1). Here, the results are different from those in Hofmann (2004), Jamal (2006), Tessler (2002a), and Hassan (2008), who all find that the effect of religiosity on the PfD is small and insignificant in Muslimmajority countries. Here, we find this effect to be negative (and small), but in ways similar to the ROW-these differences are likely to be due to differences in the sample and/or in our measurement of PfD.

The income effect, which is evident in the global sample, is neutralized in the Arab region, which has only a small upper middle class effect. In particular, the lower middle class group (Inc2) has a $2 \%$ premium on PfD in the global sample, but a zero premium in the Arab region. Thus, while it may be that it was the middle classes that mainly supported democratic ideals during the regional uprisings of 2011 (Diwan, 2013), they still fell short of the intensity of middle class support for democracy observed in the ROW. Finally, women are found to be more prodemocracy in the PfD sense then men in the Arab region, but not in the ROW, with a small differential of $1 \%$.

\footnotetext{
16 In contrast, the relation between age and DemoNet, the measure on preference for democracy relative to a hard autocracy, goes the other way around, as if older individuals are more comfortable with hard autocracy.
} 
What is the relative contribution then of age, education, class, and religiosity in explaining the Arab gap? Let us consider for simplicity that Arabs have the same distribution of age and education as in the ROW, but that religiosity is one SD above the global situation (which is close to reality-see Table 1). Let us then compare the attitudes to PfD of its main champion-a young, highly educated, lower middle class (LMC) individual, with average religious beliefs. Let us pick then a LMC youth of about 25 years old (with about one SD below the global average age, i.e., of age 43.3-16.8), that goes to university (this corresponds to a rating of 4 which is again close to an education level about one SD above the global average: $2.94+.78)$. The global educated youth is estimated to have a surplus on PfD, relative to an average global individual (i.e., with all variables are at the mean of their global distribution, the normalized PfD measure is 0 ) of 18 points $(+6+10+0+2)$. The Arab educated youth, with a religiosity level set at the Arab average, would have an excess of PfD relative to an average global citizen of 4 points $(3+3-2+0) .{ }^{17}$ The PfD difference between the Arab and global educated LMC individuals is thus 14 points (18-4), which can be decomposed into the differential effect of education (7), age (3), religiosity (2), and LMC effect (2). Clearly, the education effect swamps each of the other three effects.

\section{Civic Action and Protest}

Are the lower levels of PfD in the Arab countries that we have uncovered above associated with lower level of political involvement? The question is worth asking given the seeming contradiction between our results on the existence of a democratic preference gap, and the scenes of demonstrations and protest witnesses in major Arab cities during 2011-2012 (a period that falls between the WVS waves 5 and 6). To try to elucidate this contrast, there are several questions related to political involvement in the WVS that can be looked at here. We focus on three variables-interest in politics, participation in demonstrations, and a broad index of civic action that we construct and that encompasses four questions related to the extend to which respondents have participated in a demonstration, signed a petition, voted, or joined a boycott.

It turns out that there are no level differences in the Arab world relative to the ROW-the level Arab dummy is not significantly from zero in Table 2 (columns 7 to 9). ${ }^{18}$ But are there differences in the participation of particular groups in political activities? To answer this, we look at the slope effects associated with our 3 variables (Table 3, columns 7 to 9). The results indicate that there are important slope differences for education again, but not for most of the other individual characteristics. Although educated Arabs are more interested in politics than their global comparators (by $+16 \%$ ), they are not as engaged politically (a gap of 13\%), and they demonstrate less (a gap of $12 \%$ ) relative to similarly educated individuals in the ROW. These large differentials run parallel to our results above on the PfD gap being especially large among the educated, and it strengthens the notion that education is not as emancipatory politically in the Arab world as in the rest of the world. On the other hand, the results in Table 3 also show that youth have participated more in demonstrations than in the rest of the world (relative to older individuals), which runs against their (small) relative gap on PfD, pointing towards the existence of other countervailing influences, and requiring further investigation. ${ }^{19}$

\section{Robustness}

We conclude by conducting robustness checks to see if a few outliers countries in the Arab region drive the main results found above, or whether these apply broadly in the Arab sub-sample. To evaluate the particular country effects, we rerun the PfD regression of Table 2, replacing the Arab dummy by country dummies for each of the 12 Arab countries covered by the WVS, in order to measure how far from the regression line each Arab country lies (see Table 4). We find that all the countries of the region are below the global "regression line" on PfD. The regressions yield effects with the same signs as those in Table 2,

Table 4. Country specific effects on values (waves 5 and 6).

\begin{tabular}{lccc}
\hline & PfD & DemoGap & DemoNet \\
\hline JOR & $-0.03^{* *}$ & $-0.03^{* * *}$ & $0.09^{* * *}$ \\
MAR & 0.00 & $0.10^{* * *}$ & $0.11^{* * *}$ \\
EGY & $-0.03^{* *}$ & $0.08^{* * *}$ & $0.08^{* * *}$ \\
LBN & $-0.01^{* * *}$ & 0.01 & $-0.02^{* * *}$ \\
PLN & $-0.01^{* * *}$ & $0.03^{* * *}$ & 0.00 \\
QAT & $-0.04^{* * *}$ & na & na \\
TUN & $-0.05^{* * *}$ & $0.09^{* * *}$ & 0.00 \\
LBY & $-0.08^{* * *}$ & $0.08^{* * *}$ & $0.02^{* * *}$ \\
YEM & $-0.03^{* * *}$ & $0.05^{* * *}$ & $0.04^{* * *}$ \\
IRQ & 0.02 & $0.05^{* * *}$ & $0.08^{* *}$ \\
DZA & $-0.02^{* * *}$ & $0.02^{* * *}$ & $0.04^{* * *}$ \\
KWT & 0.00 & 0.00 & $-0.02 * *$ \\
BHR & $-0.03^{* *}$ & na & $-0.03^{* * *}$ \\
$N$ & 133108 & 126530 & 127166 \\
$R^{2}$ & 0.04 & 0.05 & 0.05 \\
\hline
\end{tabular}

Notes: Standardized beta coefficients. Also controls for all individual characteristics, GDPc, w6, w6*ARB1.

\footnotetext{
17 The last term related to the compositional effect of religiosity is computed as follows for the educated young Arab: [0.76-0.35]/.48-see Table 1.

18 Table 2 also reveals that the variables "protest" and "civic engagement" (but not "interest in politics") have fallen between waves 5 and 6 in the four countries for which data exists over the two waves. This suggests that political activism was slightly higher during the period covered by wave 5 (and was then higher than in the ROW).

19 These results confirm Tessler and Robbins (2014) results, based on Arab Barometer data, on the dominance of youth and the educated in protests in Egypt, but they go beyond these by comparing their participation rates with those of similar groups in the ROW.
} 
when they are significant. We have also run Table 2 regressions for waves 5 and 6 separately (results not shown). For PfD, there is no Arab effect in wave 5 (where the sample is much smaller), and a stronger Arab effect in wave 6 . Thus the PfD regressions are broadly similar across countries and periods, and the democratic gap uncovered above applies to every Arab country in the sample, albeit with different intensities.

\section{Conclusions}

Our investigation found, using the WVS data, which covered 12 Arab countries and 68 non-Arab countries in its $5^{\text {th }}$ and $6^{\text {th }}$ wave, that the Arab region did experience a democratic demand deficit around 2008-2013. More specifically, when focusing on the Arab region in a comparative perspective, we found that the demand for democracy was stunted by a pro status quo bias which was especially strong among the educated, but which was also visible among the youth and the middle class.

What to make of these findings? The empirical literature concerned with democratization has largely compared democratic performance across countries. As a group, Arab countries have the lowest rating in the world on democracy indexes such as the Polity index (Freund \& Jaud, 2013). While this political specificity puts the Arab world group quite apart from the rest of the world, the prevalence of autocratic regimes may be however totally unrelated to individual preferences. Indeed, most political scientists do not believe that individual preferences have a great effect on whether a country ends up democratic or not, and instead, democracy is believed to arise as an agreement among elites (Przeworski, 2010). Empirically, researchers have found many country-specific reasons, outside of individual preferences, why Arab countries have a democratic deficit (Diamond, 2010; Elbadawi \& Makdissi, 2010; Noland, 2005; Stepan \& Robertson, 2003). Some of the factors that stand out include the existence of oil rents, which favor patronage and strengthen autocracy (Ross, 2001), the effect of wars and the IsraeliPalestinian conflict which has led to oversized armies with an incentive to grab power (Elbadawi \& Makdissi, 2010), and of external interventions in support of autocrats (Stepan \& Robertson, 2003). It may also be the case that democratization is driven by changes in elite bargains, but that chances of reversals to autocracy are lower when a country's democratic culture is stronger (O'Donnel, Schmitter, \& Whitehead, 1986).

We tend to believe that individual values matter for regime type over the long-term. But in this paper, we are more concerned about the formation of individual preferences, and about whether these values are related to local culture, and thus are impervious to change, or whether they are instead related to factors that are amenable to be affected by particular policies. There is an active debate on whether this "democratic exception" is due to a cultural bias present in Arab and/or in Muslim countries. While we do not dispute that local culture can, to some extent, affect individual preferences for a democratic order, we will argue that the weight of the evidence we have uncovered points towards a larger role for political explanations, rather than towards essentialist claims.

The key question posed by our results is that of figuring out the deeper reasons shaping the low demand for democracy in Arab countries. Several possible logically coherent interpretations suggest themselves - the exception we have uncovered could conceptually be due to differences in culture, but also to differences in interests, circumstances, or active policies by autocratic governments to influence individual preferences. While the results in this paper cannot claim to disentangle these different reasons, they can at least help in making some informed speculations.

First, what do our results say about the possibility that Arab culture is inimical to democratic ideals? In our data, the neutralized effect of education on political emancipation predominate-in the example we have developed, it explains half of the democratic gap. The cultural factor is unlikely to explain the blunted impact of education in the Arab world, as local culture would be expected to affect the uneducated more than the educated, which are typically more connected to global than to local values (Norris, 2011). Moreover, if we think of Arab culture in terms of its surplus of religiosity, a possible characteristic of followers of Islam, it is apparent that in this sense also, the contribution of Arab culture to the Arab democratic gap, which we have found to exist, is small.

Which of the remaining hypotheses are more promising? It could be that individuals associate democracy with regime change, which they fear because of the probable chaos that such a transition would entail, especially in their environments where autocrats had worked hard at not facilitating such transitions. ${ }^{20}$ If this was a predominant factor, it might possibly explain the democratic gap among the lower middle class individuals, which can be particularly vulnerable to economic shocks, but there seem to be no particular reason why it would particularly affect the educated and the youth.

A fear of income redistribution argument is also unconvincing. If it was the fear of democratic governments acting to the benefit of the poor and redistributing income away from the rich that led to a low demand for democracy, we would have expected larger differences among the upper middle class and the rich, which we do not observe in our data.

There are two remaining arguments that one finds in the democratization literature that are potentially more in sync with our observations. It could be the case that

\footnotetext{
20 The extreme case being in Libya where Kaddafi had made sure that no single institution remained. Jamal and Tessler (2008) favor this interpretation. They argue that fear of instability is related to both the geo-strategic situation of the region (particularly in Iraq, Palestine, Lebanon, Algeria), and to actions by rulers to ensure that regime change would bring disorder and divisions, as a means to block the demands for political change.
} 
the youth, the educated, or the middle class, have an interest in the preservation of the status quo if they expected a more democratic regime to deliver Islamistdominated governments that would reduce their civic rights. This could be at the heart of the late version of the autocratic bargain that has managed to keep aging autocrats in power after the failure of their economic performance became clear in the 2000s. To check this hypothesis in more depth would require that the attitudes of these groups towards political Islam be looked at more carefully.

Finally, the existence of large democratic gaps among educated individuals could be either due to the fact that the educated have done particularly well in the last two decades, and/or to the ability of long-lived autocratic regimes to manipulate educational and cultural institutions in ways that bias individual values to favor their rule. These hypotheses, while attractive a priori, would be hard to check empirically in the Arab world, given the low level of variation in political regimes, and would require a broader global investigation into the relation between regime type and the extent of support by the educated for pro-autocracy values.

Trying to disentangle these hypotheses further is an important agenda for future research. But our results suggest already that rather than focus on immutable culture as the main constraint to changes in values, one needs instead to focus on what can be done on the policy front. In this respect, education emerges as an area where the focus of reforms should concentrate not just on its quality from an economic productivity perspective, but also, from the social and political qualities it embodies as well.

\section{Acknowledgements}

We want to thank Steffen Hertog, Tarek Masoud, Gerard Roland, Mohamed Saleh, Hadi Esfahani, Mark Tessler, and two anonymous referees, for specific suggestions that led to significant improvements in this paper, and Tarik Akin for his excellent assistance on the statistical work. Financing by the Economic Research Forum is gratefully acknowledged.

\section{Conflict of Interests}

The authors declare no conflict of interests.

\section{References}

Cammett, M., Diwan, I., Richards, A., \& Waterbury, J. (2015). A political economy of the Middle East. Boulder, CO: Westview Press.

Chekir, H., \& Diwan, I. (2014). Crony capitalism in Egypt. Journal of Globalization and Development, 5(2), 177-211.

Ciftci, S. (2010). Modernization, Islam, or social capital: What explains attitudes toward democracy in the
Muslim world? Comparative Political Studies, 43(11), 1442-1470.

Diamond, L. (2010). Why are there no Arab democracies? Journal of Democracy, 21(1), 93-112.

Diwan, I. (2013). Understanding revolution in the Middle East: The central role of the middle class. Middle East Development Journal, 5(1).

Elbadawi, I., \& Makdisi, S. (Eds.). (2010). Democracy in the Arab world: Explaining the deficit. London: Routledge.

Fish, M. S. (2002). Islam and authoritarianism. World Politics, 55(1), 4-37.

Freund, C., \& Jaud, M. (2013). On the determinants of democratic transitions. Middle East Development Journal, 5(1).

Hassan, R. (2008). Inside Muslim minds. Carlton, VIC: Melbourne University Publishing.

Henry, C. M., \& Springborg, R. (2010). Globalization and the politics of development in the Middle East (Vol. 1). Cambridge: Cambridge University Press.

Hofmann, S. R. (2004). Islam and democracy micro-level indications of compatibility. Comparative Political Studies, 37(6), 652-676.

Inglehart, R., \& Welzel, C. (2005). Modernization, cultural change, and democracy: The human development sequence. Cambridge: Cambridge University Press.

Inglehart, R., \& Welzel, C. (2010). Changing mass priorities: The link between modernization and democracy. Perspectives on Politics, 8(2), 551-567.

Jamal, A. A. (2006). Reassessing support for Islam and democracy in the Arab world? Evidence from Egypt and Jordan. World Affairs, 169(2), 51-63.

Jamal, A. A., \& Tessler, M. A. (2008). Attitudes in the Arab world. Journal of Democracy, 19(1), 97-110.

Lipset, S. M. (1959). Some social requisites of democracy: Economic development and political legitimacy. American Political Science Review, 53(1), 69-105.

Noland, M. (2005). Explaining Middle Eastern authoritarianism (Institute for International Economics Working Paper [05-5]). Retrieved from https://piie.com/ publications/wp/wp05-5.pdf

Norris, P. (2011). Democratic deficit: Critical citizens revisited. Cambridge: Cambridge University Press.

Norris, P., \& Inglehart, R. (2002). Islamic culture and democracy: Testing the 'clash of civilizations' thesis. Comparative Sociology, 1(3), 235-263.

O’Donnel, G., Schmitter, P., \& Whitehead, L. (1986). Transitions from authoritarian rule (Vols. 1-4). Baltimore: The John Hopkins University Press.

Owen, R. (2014). The rise and fall of Arab presidents for life: With a new afterword. Cambridge, MA: Harvard University Press.

Przeworski, A. (2010). Democracy and the limits of selfgovernment (Vol. 9). Cambridge: Cambridge University Press.

Ross, M. L. (2001). Does oil hinder democracy? World Politics, 53(3), 325-361.

Stepan, A. C., \& Robertson, G. B. (2003). An "Arab" more 
than a "Muslim" democracy gap. Journal of Democracy, 14(3), 30-44.

Tessler, M. (2002a). Islam and democracy in the Middle East: The impact of religious orientations on attitudes toward democracy in four Arab countries. Comparative Politics, 43(3-5), 337-354.

Tessler, M. (2002b). Do Islamic orientations influence attitudes toward democracy in the Arab world? Evi- dence from Egypt, Jordan, Morocco, and Algeria. International Journal of Comparative Sociology, 43(35), 229-249.

Tessler, M. A., \& Gao, E. (2005). Gauging Arab support for democracy. Journal of Democracy, 16(3), 83-97.

Tessler, M., \& Robbins, M. (2014). The Arab uprisings explained: New contentious politics in the Middle East. New York, NY: Columbia University Press.

\section{About the Authors}

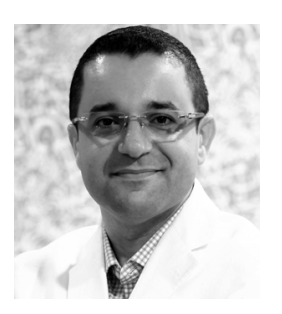

Mohamad Al-Ississ holds a doctorate degree in Public Policy from Harvard University. He currently directs Economics and Social Development in the Office of King Abdullah II of Jordan. Prior to that, he served as the associate dean of the school of Global Affairs and Public Policy at the American University of Cairo, and was on the economics faculty there. He has published in top journals on issues relating to the political economy of the Arab World, social polarization, behavioral economics and finance, and the economics of political violence and religious experience.

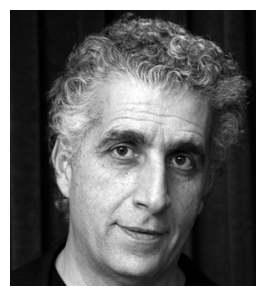

Ishac Diwan currently holds the Chaire Economie du Monde Arabe at Paris Sciences et Lettres. He received his PhD in economics from the University of California at Berkeley. He directs the Economic and Political Transformation program of the Economic Research Forum and is a research fellow at Harvard University's Middle East Initiative. He is widely published in the areas of international trade and finance, and Middle East political economy. 


\section{Annex}

\section{Definition of Variables}

Dependent Variables

Preference for democracy (PfD). This variable uses responses to the question: "People sometimes talk about what the aims of this country should be for the next ten years. In each of the 3 menus listed below, which option you consider the most important? And which would be the next most important?" PfD is defined as the number of times democratic principles (M1: 3; M2: 2; M3: 2 or 3) are listed ahead of security interests (M1: 2; M2: 1, M3: 4).

\section{Menu 1}

1. A high level of economic growth;

2. Making sure this country has strong defense forces;

3. Seeing that people have more say about how things;

4. Trying to make our cities and countryside more beautiful.

Menu 2

1. Maintaining order in the nation;

2. Giving people more say in important government decisions;

3. Fighting rising prices; 4. Protecting freedom of speech. Menu 3

1. A stable economy;

2. Progress toward a less impersonal and more humane society;

3. Progress toward a society in which Ideas count more than money;

4. The fight against crime.

Democratic Aspirations: How important is it for you to live in a country that is governed democratically?

Democratic satisfaction: How democratically is this country being governed today?

Democratic Deficit (DemoGap): Constructed as the difference between democratic aspirations and democratic satisfaction. Strong Leadership: Would having a strong leader who does not have to bother with parliament and elections be a very good, fairly good, fairly bad or very bad way of governing this country?

Democratic Net preference (DemoNet): The difference between democratic aspirations and strong leadership

Interest in Politics: Average of 2 variables: (i) How important is Politics in your life? (ii) How interested are you in politics? Civic Engagement: Average value of 4 variables: Have you ever: (i) Signed a petition"; (ii) Joined in boycotts"; (iii) Attended peaceful demonstrations; (iv) voted.

Participation in Demonstrations (protest): Have you ever: "Attended peaceful demonstrations"?

\section{Independent Variables}

Age: the scope of this variable is restricted to 15-99.

Education: A 1-4 scale where 1 stands for people who no education, 2 for individuals with at most have a primary school diploma, 3 for people who have more than primary school and less than university education and 4 for people who have at least started a university program.

Female: Takes a value of 1 for female and 0 for male.

Income: Inc1, Inc2, and Inc3 are dummy variables related to the 3 first quartiles of the income distribution respectively, relative to the group in the richest fourth quartile.

Religiosity: Whether religious faith is an important child quality.

Lngdpc: Logarithmic value of GDP per capita (PPP, constant 2005 international \$), for the year in which the survey was done (World Bank Indicators). 